\title{
Directed evolution of a fungal $\beta$-glucosidase in Saccharomyces cerevisiae
}

Kane Larue, Mindy Melgar and Vincent J. J. Martin*

\begin{abstract}
Background: $\beta$-glucosidases (BGLs) catalyze the hydrolysis of soluble cellodextrins to glucose and are a critical component of cellulase systems. In order to engineer Saccharomyces cerevisiae for the production of ethanol from cellulosic biomass, a BGL tailored to industrial bioconversions is needed.

Results: We applied a directed evolution strategy to a glycosyl hydrolase family 3 (GH3) BGL from Aspergillus niger (BGL1) by expressing a library of mutated bg/1 genes in S. cerevisiae and used a two-step functional screen to identify improved enzymes. Twelve BGL variants that supported growth of $S$. cerevisiae on cellobiose and showed increased activity on the synthetic substrate $p$-nitrophenyl- $\beta$-D-glucopyranoside were identified and characterized. By performing kinetic experiments, we found that a Tyr $\rightarrow$ Cys substitution at position 305 of BGL1 dramatically reduced transglycosidation activity that causes inhibition of the hydrolytic reaction at high substrate concentrations. Targeted mutagenesis demonstrated that the position 305 residue is critical in GH3 BGLs and likely determines the extent to which transglycosidation reactions occur. We also found that a substitution at $G \ln ^{140}$ reduced the inhibitory effect of glucose and could be combined with the Y305C substitution to produce a BGL with decreased sensitivity to both the product and substrate. Using the crystal structure of a GH3 BGL from A. aculeatus, we mapped a group of beneficial mutations to the $\beta / a$ domain of the molecule and postulate that this region modulates activity through subunit interactions. Six BGL variants were identified with substitutions in the MFa pre-sequence that was used to mediate secretion of the protein. Substitutions at Pro $^{21}$ or Val ${ }^{22}$ of the MFa pre-sequence could produce up to a twofold increase in supernatant hydrolase activity and provides evidence that expression and/or secretion was an additional factor limiting hydrolytic activity.
\end{abstract}

Conclusions: Using directed evolution on BGL1, we identified a key residue that controls hydrolytic and transglycosidation reactions in GH3 BGLs. We also found that several beneficial mutations could be combined and increased the hydrolytic activity for both synthetic and natural substrates.

Keywords: Biofuels, Consolidated bioprocessing, $\beta$-glucosidase, Cellulase, Inhibition, Directed evolution

\section{Background}

Cellulosic biorefineries offer the potential to produce fuels and other chemicals from renewable substrates [1]. While advances have been made towards economically viable bioconversion processes, the efficiency and cost of saccharolytic enzymes are obstacles that challenge the feasibility of the large-scale production of fermentable sugars from cellulosic plant biomass. A promising

\footnotetext{
*Correspondence: vincent.martin@concordia.ca

Department of Biology, Centre for Structural and Functional Genomics,

Concordia University, 7141 Sherbrooke West, Montreal, QC H4B 1R6, Canada
}

strategy is to engineer an organism that expresses a functional cellulase system that simultaneously hydrolyses biomass while fermenting hydrolysate [2-4]. Consolidated bioprocessing (CBP) would eliminate the costs of a dedicated saccharification process but depends on the development of a fermentation strain expressing a cellulase system capable of efficiently hydrolyzing cellulosic biomass at high solid loadings.

Saccharolytic enzymes from cellulolytic microbes are well characterized and are excellent candidates for industrial applications [5]. In the minimal model of cellulose hydrolysis, cellobiose and other soluble cellodextrins are released through the synergistic 
activities of endoglucanases (EGLs; EC 3.2.1.4) and cellobiohydrolases (CBHs; 3.2.1.91). $\beta$-glucosidases (BGLs; 3.2.1.21) are a third and critical component of natural and engineered cellulase systems. Their role is twofold: The hydrolysis of soluble cellodextrins by BGLs produce a fermentable sugar, glucose, while removing hydrolysate intermediates that act as inhibitors toward EGLs and CBHs [6]. Unfortunately, most characterized microbial BGLs perform best at low substrate concentrations, with $K_{m}$ values between 1-3 mM for cellobiose [7-9]. BGLs are also inhibited by glucose $[6,10]$, with reported $K_{i}$ values between 1-10 mM [11, 12]. Glucose-tolerant BGLs have been identified [13-16], but the mechanism of glucose tolerance is not understood. In addition to glucose sensitivity, inhibition of hydrolase activity is often observed at substrate concentrations above $K_{m}$, where transglycosidation reactions occur [7]. Inhibition of BGL hydrolytic activity by product and substrate contribute to limiting the efficiency of cellulosic bioconversion processes because the saccharification of biomass by EGLs and CBHs is dependent on the hydrolysis of soluble cellodextrins to glucose [17].

The yeast Saccharomyces cerevisiae is well-suited as a $\mathrm{CBP}$ platform microorganism because it naturally ferments hexose sugars to ethanol at high yields. However, S. cerevisiae is non-cellulolytic and a CBP strain designed to secrete cellulases is needed. Two challenges remain in the development of a strain of S. cerevisiae with cellulolytic activity: First, an efficient set of saccharolytic enzymes must be optimized for the hydrolysis of pretreated cellulosic biomass. Second, recombinant cellulases must be secreted at sufficient levels such that the production of sugars will support ethanol fermentation at suitable rates and yields. The heterologous expression of saccharolytic enzymes in S. cerevisiae and other hosts is well documented [18-23]. BGLs secreted from S. cerevisiae enable growth on cellobiose [24-27], and the co-expression of BGLs with other cellulases enable growth on pure cellulose or pre-treated cellulosic feedstocks [20,21, 28,29], but low ethanol yields have been reported from cellobiose $(<20 \mathrm{~g} / \mathrm{L}$ [19]) and amorphous cellulose $(<7 \mathrm{~g} / \mathrm{L}$ [30]). Experiments using Trichoderma reesei have shown that the addition of exogenous BGL to a natural cellulase system increases the efficiency of cellulose hydrolysis [31, 32]. Since S. cerevisiae secretes saccharolytic enzymes well below titers reported for other proteins [33], increasing BGL titers would likely improve fermentation yields and is therefore a key objective for CBP strain development.

BGL inhibition and low expression are compounding obstacles to the development of CBP using S. cerevisiae. With the goal of identifying the best BGL for use in industrial processes, many studies have been based on the discovery and comparative characterization of enzymes from cellulolytic organisms [11, 22, 34, 35]. Attempts have also been made at improving natural BGLs by reducing inhibition through rational design [36], the construction of gene fusions [37, 38], increasing expression via codon optimization [25], and using alternative secretion or cell anchoring strategies [25, 39, 40]. Structural data are also available for several BGLs, with representative structures from GH1 and GH3 proteins [41-43]. Despite the scope of information available, a BGL tailored to CBP is yet to be discovered or engineered [44].

Directed evolution is a proven tool for protein engineering. Using an artificial selection process to screen mutagenized proteins, enzyme function can be altered or optimized to meet specific needs $[45,46]$. The use of directed evolution to modify cellulases for industrial applications has been demonstrated on EGLs [47-49] and BGLs [50-55], where thermal stability, activity at non-natural temperatures, and $\mathrm{pH}$ optimum are most often targeted for improvement. With the goal of building a CBP strain, we applied a directed evolution strategy based on a two-step functional screen to identify enzyme variants of a GH3 BGL from Aspergillus niger using $S$. cerevisiae as a host. This strategy offers the potential to remodel a BGL for increased hydrolysis activity while improving heterologous expression in an efficient fermentation strain.

\section{Results}

\section{Directed evolution of BGL1}

We targeted the $\beta$-glucosidase from $A$. niger (BGL1) using directed evolution to adapt it towards heterologous expression S. cerevisiae. We built a fusion protein by replacing the native BGL1 signal sequence with the $S$. cerevisiae mating pheromone $\alpha$ factor (MF $\alpha$ ) pre-sequence to direct secretion of the protein into culture media. Our strategy utilized the native homologous DNA recombination machinery in S. cerevisiae to assemble a library of mutagenized bgll genes, followed by a two-step selection to identify improved mutants. Because wild-type $S$. cerevisiae lacks $\beta$-glucosidase activity (Fig. 1c; empty vector), growth on cellobiose was used as the primary selection method. We then employed an endpoint assay using pNPG as a substrate for quantitative measurement of $\beta$-glucosidase activity. To generate sequence diversity, the bgll gene was mutagenized using error-prone PCR and transformants were cultured as a mutant pool in liquid media to maximize the library size. We determined that the pooled library contained approximately $1.6-2 \times 10^{7}$ recombinant mutants by growing small quantities (0.0001-0.1\%) of the transformation mixture on solid 
a
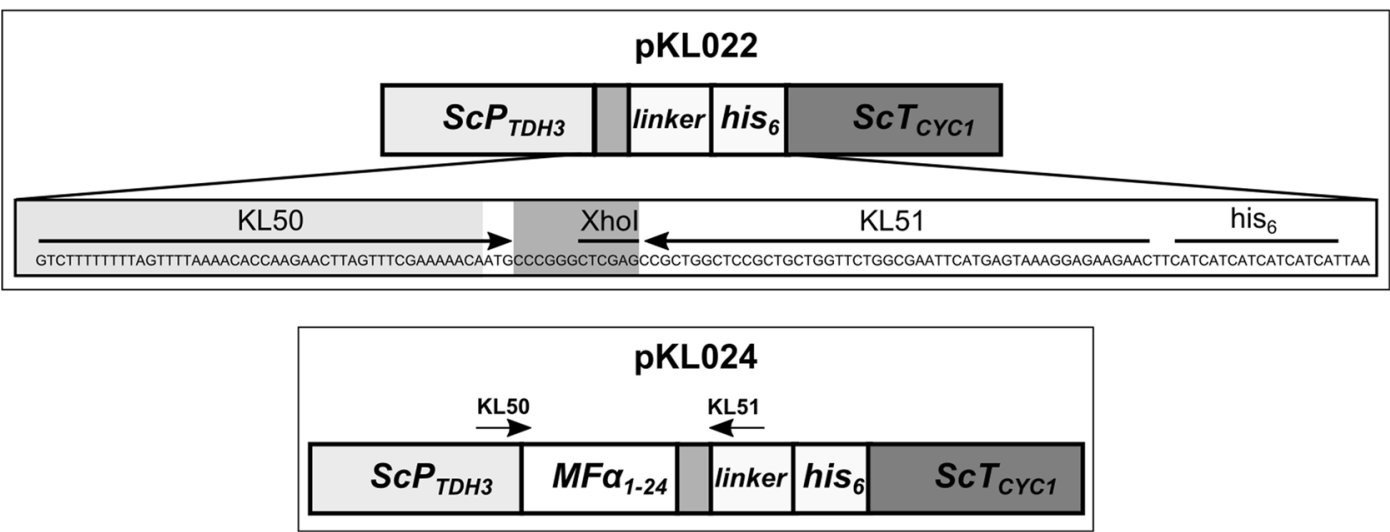

\begin{tabular}{|c|c|c|c|c|c|}
\hline \multicolumn{6}{|c|}{ pKL029 } \\
\hline \multicolumn{2}{|c|}{$\stackrel{\mathrm{KL} 50}{\longrightarrow}$} & & KL51 & & \\
\hline$S c P_{T D H 3}$ & $M F \alpha_{1-24}$ & $b g / 1_{22-860}$ & linker & $\operatorname{his}_{6}$ & $S c T_{C Y C 1}$ \\
\hline
\end{tabular}

b

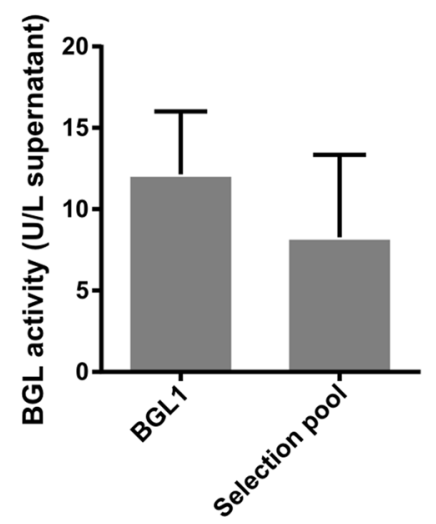

C

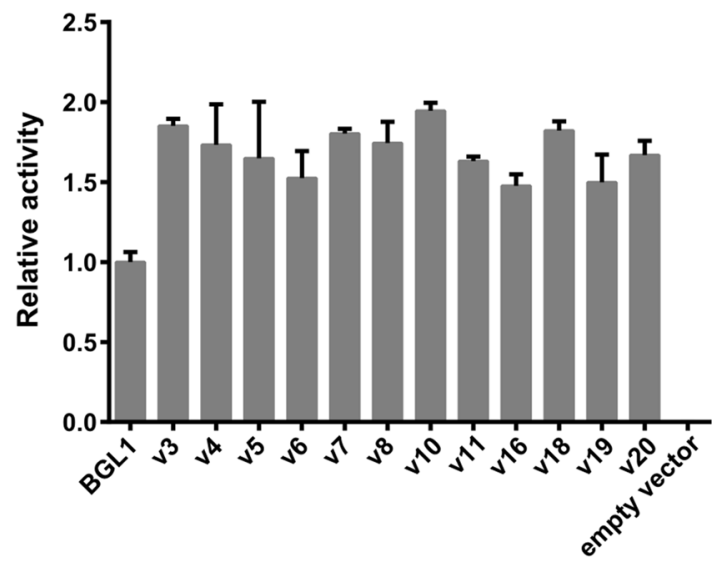

Fig. 1 Directed evolution of BGL1. a Schematic of the assembly and expression cassettes from pKL022, pKL024, and pKL029. b Activities of a wildtype population and selection pool from endpoint assays. c Activities of improved BGLs determined using time course assays. Relative enzyme activities were normalized to cell density. Error bars represent mean $\pm 95 \%$ confidence interval of triplicate experiments

media immediately after electroporation. Approximately $3 \times 10^{5}$ variants (1.5-2 \% of the total library) were subsequently screened on solid media containing cellobiose as the sole carbon source. Ninety-five percent of the mutant bgl1 library clones did not grow on cellobiose, showing that most mutations were deleterious. Colonies from the mutant pool varied in size whereas those expressing the experimental wild-type enzyme showed no observable variation. This allowed colony size to be used as a semiquantitative screen for BGL activity, as has been previously reported [56-58]. The BGL activity secreted from cells originating from the largest colonies was measured using $p$-nitrophenyl- $\beta$-D-glucopyranoside (pNPG) as the substrate and compared to cultures expressing the BGL1 protein. The mean activity of the mutant pool decreased while increasing in variability (Fig. 1b), following the predicted trend for a library of mutagenized enzymes [59]. Of 1380 variants screened, twelve mutants met the threshold cutoff for selection of wild-type $+2 \mathrm{SD}$ (Fig. 1c).

Sequencing showed that the mutant bgll genes each had 3-9 nucleotide substitutions (Table 1), corresponding to a mutation rate of $1.6 \pm 0.4 \mathrm{bp}$ per $\mathrm{kb}$. Certain mutations occurred in multiple variants $(65 \mathrm{~T}>\mathrm{A}: \mathrm{v} 7$ and v18; $65 \mathrm{~T}>\mathrm{C}$ : v4 and v19; 428A > T: v5 and v20 and $1707 \mathrm{C}>\mathrm{T}: \mathrm{v} 4$ and v6). Six variants had mutations 
Table 1 Characterization of improved BGLs

\begin{tabular}{|c|c|c|c|c|}
\hline Variant & Mutation & Amino acid & Substitution & Relative activity \\
\hline \multirow[t]{3}{*}{ v3 } & $923 \mathrm{~A}>\mathrm{G}$ & 305 & Tyr $\rightarrow$ Cys & $1.68 \pm 0.02$ \\
\hline & $1557 \mathrm{~A}>\mathrm{T}$ & 516 & - & $1.05 \pm 0.01$ \\
\hline & $1934 A>T$ & 642 & $\mathrm{Glu} \rightarrow \mathrm{Val}$ & $0.80 \pm 0.03$ \\
\hline \multirow[t]{4}{*}{$v 4^{\mathrm{a}}$} & $65 \mathrm{~T}>\mathrm{C}$ & 22 & $\mathrm{Val} \rightarrow \mathrm{Ala}$ & $1.57 \pm 0.06$ \\
\hline & $174 \mathrm{~A}>\mathrm{T}$ & 55 & - & \\
\hline & $465 C>T$ & 152 & - & \\
\hline & $1707 C>T$ & 566 & - & $0.98 \pm 0.03$ \\
\hline \multirow[t]{3}{*}{ v5 } & $428 \mathrm{~A}>\mathrm{T}$ & 140 & Gln $\rightarrow$ Leu & $1.56 \pm 0.05$ \\
\hline & $2067 \mathrm{~A}>\mathrm{T}$ & 686 & - & $1.03 \pm 0.02$ \\
\hline & $2103 T>A$ & 698 & - & $1.07 \pm 0.03$ \\
\hline \multirow[t]{3}{*}{ v6 } & $917 \mathrm{~T}>\mathrm{C}$ & 303 & $\mathrm{Val} \rightarrow \mathrm{Ala}$ & $1.09 \pm 0.04$ \\
\hline & $1707 C>T$ & 566 & - & $0.98 \pm 0.03$ \\
\hline & $1818 \mathrm{~T}>\mathrm{C}$ & 603 & - & $1.05 \pm 0.04$ \\
\hline \multirow[t]{7}{*}{$v 7^{\mathrm{a}}$} & $65 \mathrm{~T}>\mathrm{A}$ & 22 & $\mathrm{Val} \rightarrow \mathrm{Asp}$ & $2.03 \pm 0.08$ \\
\hline & $297 T>C$ & 96 & - & \\
\hline & $643 A>G$ & 212 & Ile-Val & \\
\hline & $892 \mathrm{~T}>\mathrm{C}$ & 295 & - & \\
\hline & $1814 A>G$ & 602 & Lys $\rightarrow$ Arg & \\
\hline & 2019T > C & 670 & - & \\
\hline & $2079 T>A$ & 690 & - & \\
\hline \multirow[t]{9}{*}{$v 8^{a}$} & $25 G>A$ & 9 & $\mathrm{Ala} \rightarrow \mathrm{Thr}$ & \\
\hline & $60 \mathrm{~T}>\mathrm{A}$ & 20 & - & \\
\hline & $61 C>A$ & 21 & Pro $\rightarrow$ Thr & $1.77 \pm 0.02$ \\
\hline & $93 \mathrm{~T}>\mathrm{C}$ & 28 & - & \\
\hline & $462 T>C$ & 151 & - & \\
\hline & $981 \mathrm{C}>\mathrm{T}$ & 324 & - & \\
\hline & $1158 \mathrm{C}>\mathrm{T}$ & 383 & - & \\
\hline & $1953 C>T$ & 648 & - & \\
\hline & $2389 A>C$ & 794 & Lys $\rightarrow$ Gln & \\
\hline \multirow[t]{3}{*}{ v10 } & $1180 T>C$ & 391 & - & $0.90 \pm 0.02$ \\
\hline & $1448 C>T$ & 480 & $\mathrm{Ala} \rightarrow \mathrm{Val}$ & Not determined \\
\hline & $1506 \mathrm{~T}>\mathrm{A}$ & 499 & - & $0.88 \pm 0.05$ \\
\hline \multirow[t]{4}{*}{$\mathrm{v} 11^{\mathrm{a}}$} & $61 C>T$ & 21 & Pro $\rightarrow$ Ser & $1.93 \pm 0.02$ \\
\hline & $366 \mathrm{~T}>\mathrm{C}$ & 119 & - & \\
\hline & $954 \mathrm{C}>\mathrm{T}$ & 315 & - & \\
\hline & $1773 C>T$ & 588 & - & \\
\hline \multirow[t]{3}{*}{ v16 } & $681 T>C$ & 224 & - & $0.86 \pm 0.01$ \\
\hline & $1489 A>C$ & 494 & Lys $\rightarrow$ Gln & $1.17 \pm 0.06$ \\
\hline & $1678 A>G$ & 557 & Asn $\rightarrow$ Asp & $1.19 \pm 0.06$ \\
\hline \multirow[t]{2}{*}{$\mathrm{V} 18^{\mathrm{a}}$} & $65 \mathrm{~T}>\mathrm{A}$ & 22 & $\mathrm{Val} \rightarrow \mathrm{Asp}$ & $2.03 \pm 0.08$ \\
\hline & $1983 C>T$ & 658 & - & \\
\hline \multirow[t]{5}{*}{$\mathrm{v} 19^{\mathrm{a}}$} & $65 \mathrm{~T}>\mathrm{C}$ & 22 & $\mathrm{Val} \rightarrow \mathrm{Ala}$ & $1.57 \pm 0.06$ \\
\hline & $219 G>A$ & 70 & - & \\
\hline & $1275 A>G$ & 422 & - & \\
\hline & $2367 T>G$ & 786 & - & \\
\hline & $2441 C>T$ & 811 & Thr $\rightarrow$ Met & \\
\hline \multirow[t]{3}{*}{ v20 } & $428 \mathrm{~A}>\mathrm{T}$ & 140 & Gln $\rightarrow$ Leu & $1.56 \pm 0.05$ \\
\hline & $1925 \mathrm{~A}>\mathrm{T}$ & 639 & Lys $\rightarrow$ Met & $0.73 \pm 0.04$ \\
\hline & $2349 \mathrm{~T}>\mathrm{A}$ & 780 & - & $0.94 \pm 0.01$ \\
\hline
\end{tabular}

a Variants for which only signal sequence mutations at residues 21 or 22 were investigated encoding amino acid substitutions immediately following the predicted MF $\alpha$ signal peptide cleavage site at Pro ${ }^{21}$ or $\mathrm{Val}^{22}$. These two amino acids were targeted by four substitutions (P21T, P21S, V22D, and V22A). Using the prevalence of substitutions at positions 21 and 22 of the MF $\alpha$ pre-sequence, we divided the evolved BGL1s into two groups based on the presence or absence of substitutions at $\mathrm{Pro}^{21}$ and $\mathrm{Val}^{22}$. For the group of BGLs with signal peptide substitutions, we constructed genes with single mutations encoding the P21T, P21S, V22D, and V22A. For the remaining BGL1 variants, we constructed genes to test all of the mutations individually. We chose to include silent mutations in our experiments to investigate if codon optimization had occurred. All of the substitutions tested at positions 21 and 22 produced increases in activity similar to those of their parental evolved enzymes containing two or more mutations (Table 1), indicating that mutations in the MF $\alpha$ pre-sequence increased protein secretion to the culture media. None of the silent mutations tested produced observable increases in activity. We were able to establish a relationship between the increase in activity observed for several of the evolved BGLs and a single amino acid substitution (v3: Y305C; v5 and v20: Q140L; v10: A480V), but none of the mutations tested individually could account for the activities of v6 and v16 (Table 1). The K494Q and N557D substitutions did produce significant and reproducible improvements (117 and $119 \%$, respectively), suggesting a cumulative effect that contributed to the $147 \%$ increase in activity observed for v16. We chose to characterize the A480V substitution $(1448 \mathrm{C}>\mathrm{T})$ in the genetic context of v10 since the other mutations present in the gene $(1180 \mathrm{C}>\mathrm{T}$ and $1506 \mathrm{~T}>\mathrm{A}$ ) were silent and did not produce any improvements when tested alone.

\section{Kinetic characterization of BGL mutants using PNPG}

We further characterized the substitutions producing the greatest improvements with kinetic experiments. Initial reaction velocities were measured for each BGL variant at different substrate concentrations (0.1-10 mM pNPG) and at different inhibitor concentrations (0-100 mM glucose) (Table 2). Wild-type and all single substitution variants, except Y305C, were fitted to a substrate inhibition model (Fig. 2). Y305C showed no inhibition at high substrate concentrations and the reaction velocities were fitted to the Michaelis-Menten equation using a competitive inhibition model (Fig. 2). Most of the variants showed an increase in ${ }_{\text {app }} V_{\text {max }}$ similar to the relative activities reported from activity assays at $2 \mathrm{mM}$ pNPG. No other significant differences were observed in reaction kinetics between BGL1 and the mutant enzymes. Based on the change in kinetic profile caused by the Cys substitution at position 305, we used Y305C as a 
Table 2 Kinetic parameters of BGL1 and evolved variants for synthetic substrate

\begin{tabular}{|c|c|c|c|c|}
\hline & ${ }_{a p p} K_{m}(\mathrm{mM})$ & 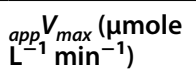 & $\begin{array}{l}{ }_{a p p} K_{\text {iglucose }} \\
(\mathrm{mM})\end{array}$ & $\begin{array}{l}a p p K_{i p N P G} \\
(\mathrm{mM})\end{array}$ \\
\hline BGL1 & $0.82 \pm 0.12$ & $118.5 \pm 10.6$ & - & $2.98 \pm 0.46$ \\
\hline V22D & $0.93 \pm 0.23$ & $210.5 \pm 31.6$ & - & $2.98 \pm 0.75$ \\
\hline Q140L & $1.09 \pm 0.06$ & $249.6 \pm 9.2$ & - & $3.41 \pm 0.21$ \\
\hline Y305C & $0.77 \pm 0.03$ & $149.7 \pm 1.7$ & $1.81 \pm 0.08$ & - \\
\hline A480V & $0.98 \pm 0.25$ & $217.7 \pm 34.3$ & - & $3.26 \pm 0.87$ \\
\hline K494Q & $0.89 \pm 0.12$ & $141.5 \pm 11.1$ & - & $3.06 \pm 0.41$ \\
\hline N557D & $0.88 \pm 0.09$ & $186.2 \pm 11.0$ & - & $3.16 \pm 0.32$ \\
\hline
\end{tabular}

background to further explore the contributions of the V22D, Q140L, and A480V substitutions. We engineered V22D/Y305C, Q140L/Y305C, Y305C/A480V doublesubstitution variants and a quadruple DLCV (V22D/ $\mathrm{Q} 140 \mathrm{~L} / \mathrm{Y} 305 \mathrm{C} / \mathrm{A} 480 \mathrm{~V})$ variant. Reaction velocities for all of the combinatorial variants were modeled using the Michaelis-Menten equation and kinetic parameters were determined (Table 3). As expected, the addition of V22D, $\mathrm{Q} 140 \mathrm{~L}$, and $\mathrm{A} 480 \mathrm{~V}$ to $\mathrm{Y} 305 \mathrm{C}$ increased the ${ }_{\text {app }} V_{\text {max }}$ for each enzyme. ${ }_{a p p} K_{m}$ and ${ }_{\text {app }} K_{i \text { glucose }}$ for V22D/Y305C and $\mathrm{Y} 305 \mathrm{C} / \mathrm{A} 480 \mathrm{~V}$ were similar to $\mathrm{Y} 305 \mathrm{C}$, while the inhibitory effect of glucose was slightly reduced for Q140L/ Y305C and DLCV.

\section{Structural mapping of BGL substitutions}

We used the three-dimensional structure of Aspergillus aculeatus BGL1 (AaBGL1) [41] to map the hypothetical position of the substitutions identified through directed evolution (Fig. 3a). Multiple sequence alignments suggest that BGL1 and other closely related fungal GH3 BGLs would adopt a three-dimensional structure similar to AaBGL1. BGL1 shares $83 \%$ sequence identity with
AaBGL1, and residues forming the active site are well conserved (Fig. 3b, d). The Q140L substitution maps to the triosephosphate isomerase domain (AaBGL1 Leu ${ }^{19}$ $\operatorname{Ser}^{356}$ ) and is $9.1 \AA$ from the closest substrate-binding residue (AaBGL1 $\operatorname{Trp}^{280}$ ) and is approximately $10 \AA$ from the $\beta / \alpha$ sandwich domain. The A480V, K494Q, and N557D substitutions are located on the $\beta / \alpha$ sandwich domain (AaBGL1 $\mathrm{Gln}^{385}-\mathrm{Gly}^{588}$ ) that contributes two active site residues (AaBGL1 $\mathrm{Glu}^{509}$ and $\mathrm{Tyr}^{511}$ ) and also forms the major interface between subunits. The A480V $\left(\mathrm{AaBGL1} \mathrm{Ile}^{480}\right.$ ) substitution is located on the surface of each subunit buried between the dimer interface. Both the K494Q and the N557D mutations (AaBGL1 Lys ${ }^{494}$ and $\mathrm{Asp}^{557}$ ) are located on the surface of the molecule. Lys $^{494}$ is also proximal to the dimer interface, though it does not contact the opposite subunit directly. The Y305C substitution maps to a short loop (AaBGL1 $\mathrm{Gly}^{294}-\mathrm{Gly}^{313}$ ) that inserts directly into the +1 subsite of AaBGL1 along with $\operatorname{Trp}^{68}$ and $\operatorname{Tyr}^{511}$. The structure of AaBGL1 in complex with thiocellobiose shows the contribution of $\mathrm{Phe}^{305}$ in the substrate-binding pocket, where the ligand docks in a narrow cleft between the three +1 subsite residues. Since the Cys functional group is less bulky than Tyr, we assume that the +1 subsite of

Table 3 Kinetic parameters of Y305C substituted variants for synthetic substrate

\begin{tabular}{|c|c|c|c|}
\hline & ${ }_{a p p} K_{m}(\mathrm{mM})$ & $\begin{array}{l}a p p V_{\text {max }}(\mu \text { mole } \\
\left.\mathrm{mg}^{-1} \min ^{-1}\right)\end{array}$ & ${ }_{a p p} K_{i \text { glucose }}(\mathrm{mM})$ \\
\hline Y305C & $0.93 \pm 0.04$ & $71.0 \pm 0.9$ & $1.92 \pm 0.10$ \\
\hline $\mathrm{V} 22 \mathrm{D} / \mathrm{Y} 305 \mathrm{C}$ & $1.06 \pm 0.04$ & $127.4 \pm 1.3$ & $2.22 \pm 0.09$ \\
\hline Q140L/Y305C & $1.32 \pm 0.05$ & $111.1 \pm 1.4$ & $3.18 \pm 0.15$ \\
\hline Y305C/A480V & $1.06 \pm 0.05$ & $124.3 \pm 1.8$ & $2.22 \pm 0.12$ \\
\hline DLCV & $1.69 \pm 0.08$ & $221.3 \pm 3.6$ & $3.37 \pm 0.18$ \\
\hline
\end{tabular}

BGL1

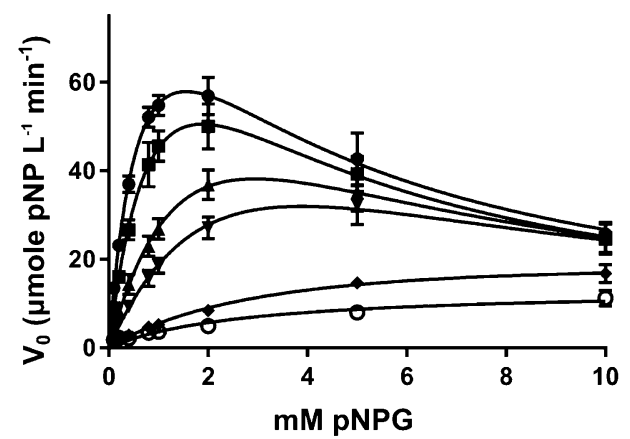

Y305C

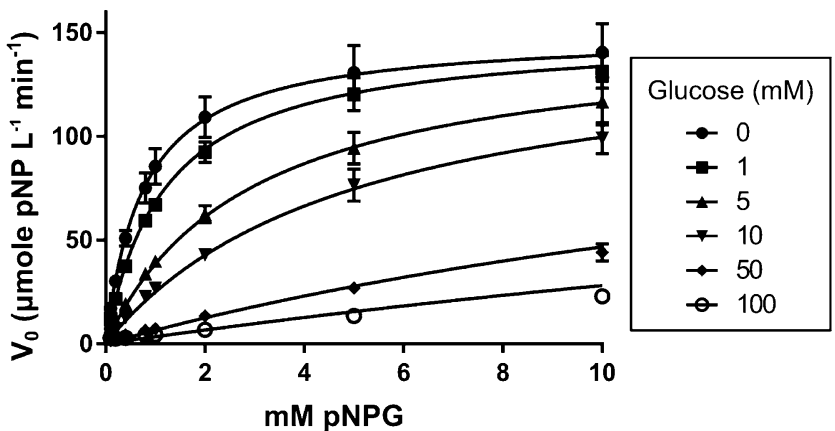

Fig. 2 Representative $V_{0}$ versus substrate concentration plots for the production of pNP at a range of pNPG concentrations in the presence of inhibitor 
a

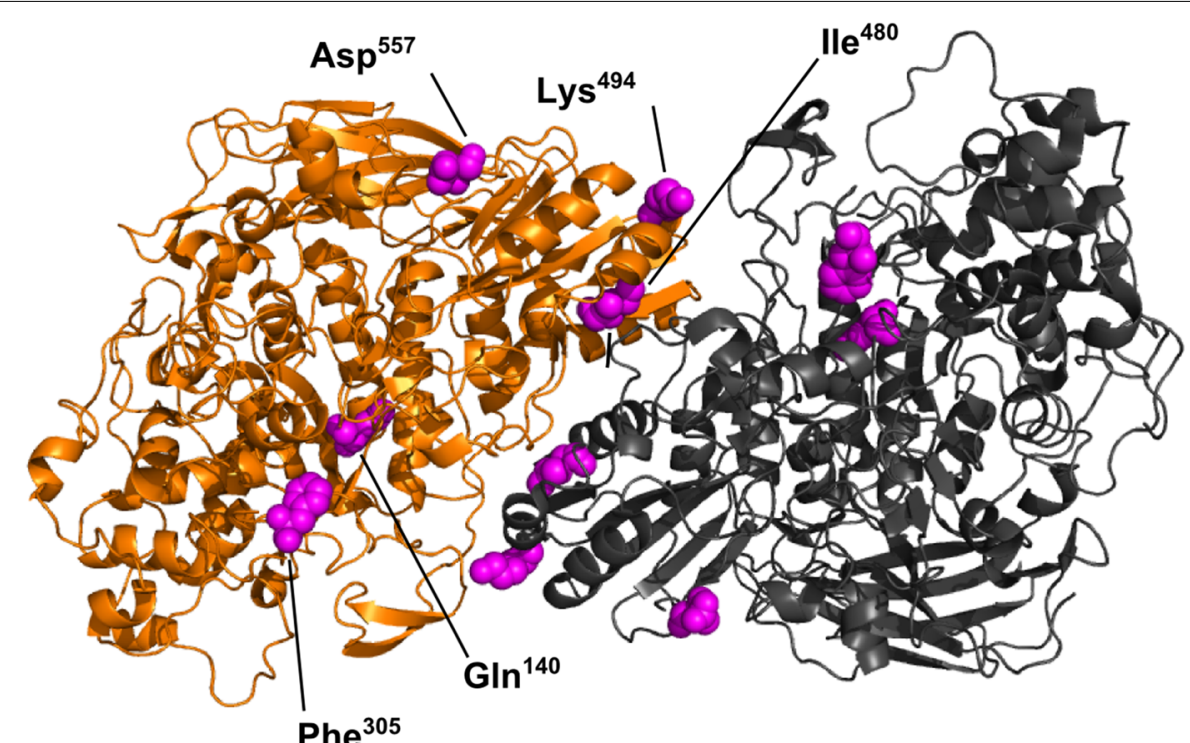

$\mathrm{Phe}^{305}$

b

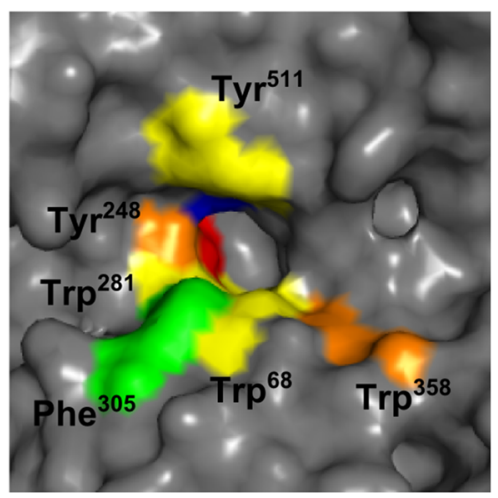

c

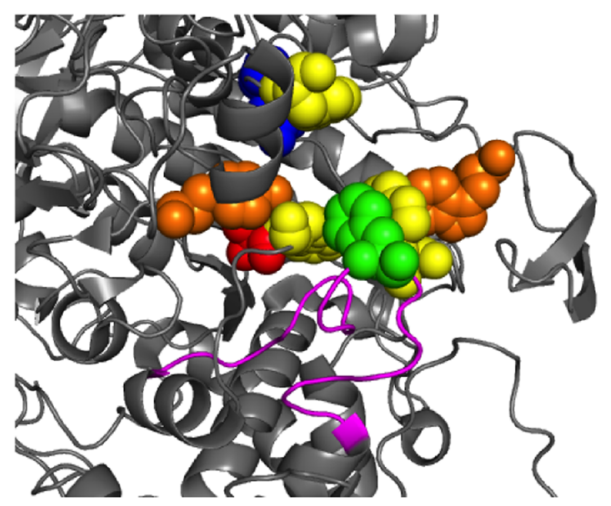

d

$\begin{array}{llllllllllllll} & 68 & 140 & 248 & 280 & 281 & 305 & 358 & 480 & 494 & 509 & 511 & 557 \\ \text { A. acu } & \text { W } & \text { Q } & \text { Y } & \text { D } & \text { W } & \text { F } & \text { W } & \text { I } & \text { K } & \text { E } & \text { Y } & \text { D* } \\ \text { A. } n i g & \text { W } & \text { Q } & \text { Y } & \text { D } & \text { W } & \text { Y } & \text { W } & \text { A } & \text { K } & \text { E } & \text { Y } & \text { N } \\ \text { A. } \text { nid } & \text { W } & \text { I } & \text { Y } & \text { D } & \text { W } & \text { W } & \text { W } & \text { Y } & \text { T } & \text { E } & \text { Y } & \text { E } \\ \text { A. fum } & \text { W } & \text { L* } & \text { Y } & \text { D } & \text { W } & \text { F } & \text { W } & \mathrm{V}^{*} & \text { S } & \text { E } & \text { F } & \text { D* } \\ \text { N. cra } & \text { W } & \text { L* } & \text { Y } & \text { D } & \text { W } & \text { F } & \text { W } & \mathrm{V}^{*} & \text { S } & \text { E } & \text { F } & \text { T } \\ \text { F. gra } & \text { W } & \text { A } & \text { Y } & \text { D } & \text { W } & \text { F } & \text { W } & \text { I } & \text { S } & \text { E } & \text { Y } & \text { T } \\ \text { P. bla1 } & - & \text { Q } & \text { Y } & \text { D } & \text { W } & \text { F } & \text { V } & \text { S } & \text { S } & \text { E } & \text { Y } & \text { P } \\ \text { U. may1 } & \text { W } & \text { W } & \text { Y } & \text { D } & \text { W } & \text { C* } & \text { F } & \text { N } & \text { N } & \text { E } & \text { Y } & \text { E } \\ \text { C. cin } & - & \text { A } & \text { Y } & \text { D } & \text { W } & \text { F } & \text { F } & \text { L } & \text { R } & \text { E } & \text { Y } & \text { E } \\ \text { P. bla2 } & \text { W } & \text { Q } & \text { Y } & \text { D } & \text { W } & \text { F } & \text { V } & \text { S } & \text { K } & \text { E } & \text { Y } & \text { P } \\ \text { R. ory1 } & \text { W } & \text { Q } & \text { Y } & \text { D } & \text { W } & \text { G } & \text { T } & \text { H } & \text { K } & \text { E } & \text { Y } & \text { P } \\ \text { R. ory2 } & \text { W } & \text { L* } & \text { Y } & \text { D } & \text { W } & \text { F } & \text { T } & \text { S } & \text { K } & \text { E } & \text { Y } & \text { P } \\ \text { R. ory3 } & \text { W } & \text { M } & \text { Y } & \text { D } & \text { W } & \text { Y } & \text { V } & \text { S } & \text { K } & \text { E } & \text { Y } & \text { P } \\ \text { R. ory4 } & \text { Y } & \text { M } & \text { Y } & \text { D } & \text { W } & \text { V } & \text { V } & \text { S } & \text { K } & \text { E } & \text { I } & \text { P } \\ \text { R. ory5 } & \text { W } & \text { Q } & \text { Y } & \text { D } & \text { W } & \text { F } & \text { V } & \text { Y } & \text { A } & \text { E } & \text { F } & \text { P } \\ \text { U. may2 } & - & \text { W } & \text { Y } & \text { D } & \text { W } & \text { A } & \text { T } & \text { H } & \text { N } & \text { E } & - & \text { E }\end{array}$

Fig. 3 Structure/function analysis of beneficial mutations in GH3 BGLs. a Molecular mapping of mutations using the A. aculeatus BGL1 crystal structure (PDB 4IIB). Chain A orange; Chain B gray. Substitutions identified by mutagenesis and functional selection are shown in magenta and labeled on Chain A. b Residues contributing to the substrate-binding pocket of A. aculeatus BGL1. c Gly ${ }^{294}-G l y^{313}$ residues (magenta) coordinate Phe ${ }^{305}$ (green) in the +1 subsite. d Alignments of $\mathrm{GH} 3$ residues. Residues identified by directed evolution are underlined. Asterisks $\left({ }^{*}\right)$ indicate beneficial substitutions found in nature. A. acu Aspergillus aculeatus BGL1; A. nig Aspergillus niger BGL1; A. nid Apergillus nidulans; A. fum Aspergillus fumigatus; N. cra Neurospora crassa; F. gra Fusarium graminearum; P. bla Phycomyces blaskesleeanus; U. may Ustilago maydis; C. cin Coprinopsis cinerea; R. ory Rhizopus oryzae. Color coding corresponds between (b), (c), and (d). Multiple sequence alignments were performed using Clustal Omega [73]. Structural analyses were performed using PyMOL 
the Y305C variant is more open and has a lower affinity for substrate.

\section{Targeted mutagenesis}

To determine if residue 305 controls hydrolytic versus transglycosidase activities in other homologs, we investigated the relative location in other GH3 BGLs (Fig. 3d). Phe is the most common residue at position $305(9 / 16$ sequences) and has a similar aromatic functional group as the Tyr residue from BGL1. The position was variable in the remaining seven homologs and included a Cys residue in the BGL from Ustilago maydis, which would suggest that its active site is similar to the Y305C variant. We sought to further test the functional significance of this position by constructing Y305F, Y305W, Y305G, Y305V, and Y305A BGL1 variants. The Y305F BGL1 variant had a similar kinetic profile to the wild-type enzyme, demonstrating inhibition at high substrate concentrations (Table 4). However, the Y305F variant had a lower app $K_{m}$ and higher app $K_{i \text { pNPG }}$ than BGL1, suggesting a slight change in affinity for acceptor at the +1 subsite. Substituting $\mathrm{Tyr}^{305}$ with Ala, Val, or Gly produced kinetics similar to the Y305C mutant, demonstrating saturation at high substrate concentrations. Sequence alignments identified a Trp residue in the BGL from Aspergillus nidulans, but the Y305W variant was non-functional and suggests that the bulky functional group blocked the substrate-binding pocket. Closer inspection of sequence alignments shows that the loop coordinating position 305 residue $\left(\right.$ Gly $^{294}-$ Gly $^{313}$ ) (Fig. 3c) contains a short variable region (residues 303-309) between two highly conserved sequences $\left(\mathrm{Gly}^{294}-\mathrm{Asp}^{302}\right.$ and $\mathrm{Ser}^{310}-\mathrm{Gly}^{313}$ ). The corresponding variable region from the $A$. nidulans $\mathrm{BGL}$ $\left({ }^{438}\right.$ GLHWADG $\left.{ }^{444}\right)$ includes an additional residue. It is likely that the Trp residue does not occupy the +1 subsite in the A. nidulans homolog and either a His or Ala is present in the substrate-binding pocket of the enzyme. Alternatively, the additional residue in the $A$. nidulans sequence could change the orientation of the Trp residue in the +1 subsite such that the substrate-binding pocket is not blocked.

Table 4 Kinetic parameters of $\mathrm{Tyr}^{305}$ variants for synthetic substrate

\begin{tabular}{|c|c|c|c|}
\hline & ${ }_{a p p} K_{m}(\mathrm{mM})$ & ${ }_{a p p} V_{\max }\left(\mu\right.$ mole $\left.\mathrm{L}^{-1} \min ^{-1}\right)$ & ${ }_{a p p} K_{i \mathrm{pNPG}}(\mathrm{mM})$ \\
\hline Y305F & $0.46 \pm 0.04$ & $126.5 \pm 5.4$ & $4.78 \pm 0.44$ \\
\hline Y305W $\mathrm{W}^{\mathrm{a}}$ & NA & NA & NA \\
\hline Y305G & $1.16 \pm 0.06$ & $239.7 \pm 3.9$ & - \\
\hline Y305A & $1.55 \pm 0.06$ & $238.2 \pm 4.1$ & - \\
\hline Y305 V & $1.14 \pm 0.08$ & $233.9 \pm 5.6$ & - \\
\hline
\end{tabular}

a Inactive under all tested conditions

\section{Enzyme kinetics using natural substrate}

Since selection in our screening strategy was based on the hydrolysis of cellobiose, we also investigated reaction kinetics using the natural substrate for wild-type and mutant enzymes. The production of glucose was measured at different cellobiose concentrations for BGL1, Y305C, Y305G, and DLCV enzymes and kinetic parameters were determined (Table 5). The results were consistent with experiments using synthetic substrate, where the wild-type enzyme showed inhibition at high cellobiose concentrations (Fig. 4a). Y305C, Y305G, and DLCV were modeled using Michaelis-Menten kinetics, showing saturation and high substrate concentrations (Fig. 4b).

\section{TLC analysis of reaction products}

Transglycosidation reactions catalyzed by BGLs with natural and synthetic acceptors are thought to be the cause of inhibition at high substrate concentrations

Table 5 Kinetic parameters of BGLs for natural substrate

\begin{tabular}{|c|c|c|c|}
\hline & ${ }_{a p p} K_{m}(\mathrm{mM})$ & ${ }_{a p p} V_{\text {max }}\left(\mu\right.$ mole $\left.\mathrm{L}^{-1} \min ^{-1}\right)$ & ${ }_{a p p} K_{i \text { cellobiose }}(\mathrm{mM})$ \\
\hline BGL1 & $1.2 \pm 0.1$ & $61.9 \pm 2.5$ & $32.4 \pm 4.5$ \\
\hline Y305C & $5.3 \pm 0.6$ & $106.4 \pm 3.4$ & - \\
\hline Y305G & $5.6 \pm 0.7$ & $122.4 \pm 4.3$ & - \\
\hline DLCV & $3.6 \pm 0.3$ & $207.5 \pm 4.3$ & - \\
\hline
\end{tabular}
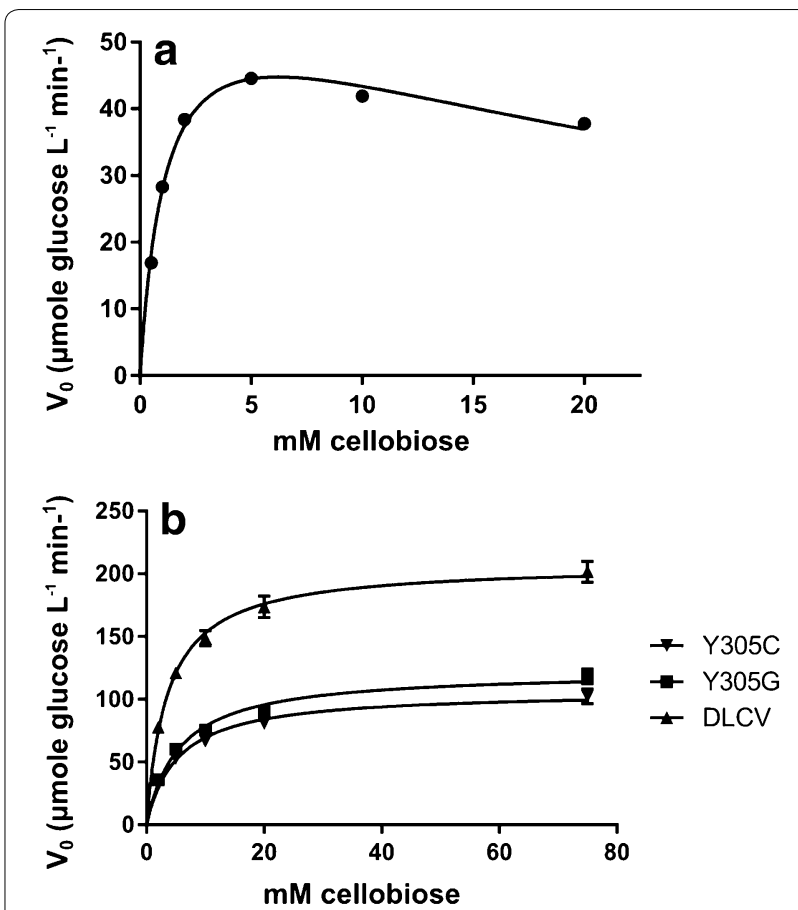

Fig. 4 Reaction rates for the production of glucose at a range of cellobiose concentrations. a BGL 1 ; b engineered variants 
[7-9, 12, 60-64]. Since kinetic experiments suggested that the transglycosidation activity of BGL1 was lost by substituting Tyr ${ }^{305}$ with either Cys, Gly, Ala, or Val residues, we performed thin-layer chromatography (TLC) analysis of reactions at high substrate concentrations (Fig. 5a, b). Kinetic experiments showed that BGL1 is strongly inhibited by synthetic substrate, where $V_{0}$ was reduced by approximately $50 \%$ at $10 \mathrm{mM}$ pNPG. Analysis of reaction products confirmed that BGL1 and the
Y305F variant were inhibited at $40 \mathrm{mM}$ pNPG, and a pNPG transglycosidation product was found to accumulate through the duration of the experiment. In contrast, both the Y305C and Y305G substituted variants completely consumed the substrate within $3 \mathrm{~h}$. A transient transglycosidation species was detected, but glucose was the major product by $4 \mathrm{~h}$ and shows that the transglycosidation reaction was reduced but not completely eliminated.

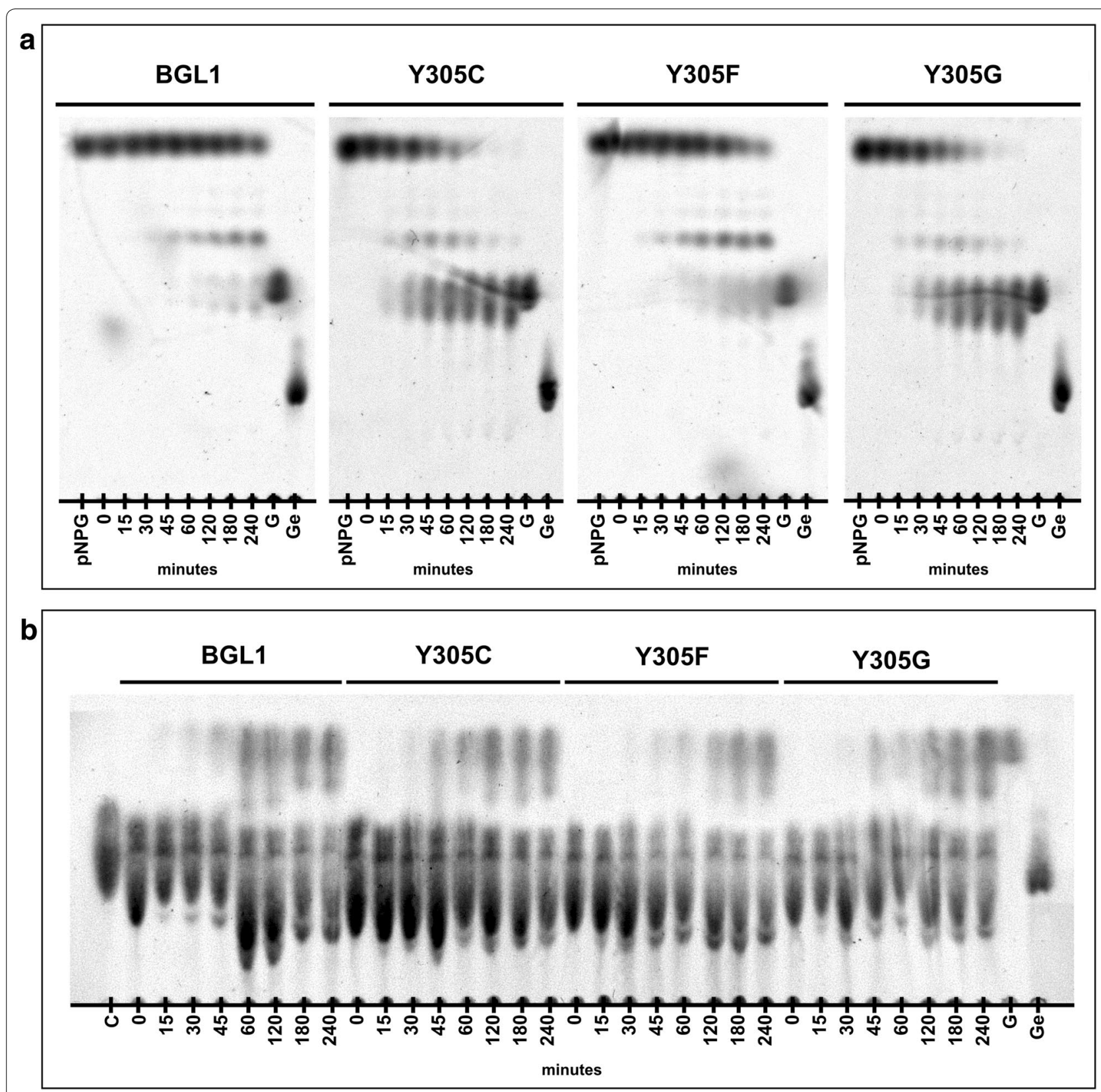

Fig. 5 Thin-layer chromatography of BGL reactions using (a) 40 mM pNPG and (b) 50 mM cellobiose. Standards (1 $\mu$ l) were 40 mM pNPG, 50 mM cellobiose (C), $50 \mathrm{mM}$ glucose (G), and $25 \mathrm{mM}$ gentiobiose (Ge) 
BGL reactions with natural substrate maintain a dynamic equilibrium since reaction species can participate in either hydrolytic or transglycosidation reactions [7, 8]. TLC analysis of reactions using BGL1, Y305C, Y305F, and Y305G at $50 \mathrm{mM}$ cellobiose showed that the transglycosidation reactions were present for all of the tested enzymes and is consistent with the presence of transglycosidation product in reactions using pNPG. Since kinetic experiments showed lower inhibition of hydrolytic activity in reactions using a natural substrate than reactions using a synthetic substrate, we suspect that TLC analysis under these conditions lacks the sensitivity to differentiate wild-type and mutant BGLs.

\section{Discussion}

In this study we tested a library of mutant $A$. niger BGL1 proteins using a two-step functional screen and identified several improved enzymes. In order to better understand the mechanisms of improvement, kinetic experiments were performed using the wild-type enzyme and several of the evolved variants. The most important finding showed that a Y305C substitution dramatically changed the kinetic parameters for both synthetic and natural substrates, reducing the inhibitory effect of high substrate concentrations towards the hydrolytic reaction. To our knowledge, these are the first experiments establishing the functional significance of the amino acid at position 305 in GH3 BGLs. BGLs have been extensively studied and inhibition by glucose and high substrate concentrations are well documented. These two characteristics limit the use of BGLs in industrial applications since high substrate loadings and the complete conversion of substrate to glucose are desirable.

Inhibition of the hydrolytic reaction at high substrate concentrations is evident in kinetic plots with non-saturating profiles $[7,8,12,36,64]$. We observed decreasing hydrolytic rates at substrate concentrations above $K_{m}$ for BGL1 and the evolved mutants, with the exception of Y305C. This kinetic profile is consistent with previous reports and is caused by a competing transglycosidation reaction in which substrate also acts as an acceptor in the +1 subsite $[8,64]$. Since the hydrolysis reaction of the Y305C variant lacked inhibition at high substrate concentrations, we investigated position 305 in several homologs and found that Phe was the most prevalent amino acid, while Tyr was only present in AnBGL1 and a homolog from Rhizopus oryzae. We used site-directed mutagenesis of the $b g l 1$ gene to test all of the residues identified by multiple sequence alignments and found that other substitutions with small functional groups (Gly, Ala, and Val) caused a similar loss of inhibition as the Y305C substitution. The Phe-substituted variant had a nearly identical kinetic profile as the wild-type Tyr, although the $\mathrm{Phe}^{305}$ variant was slightly less inhibited at high substrate concentrations than wild-type (BGL1 $K_{i \mathrm{pNPG}}=2.98 \pm 0.46 \mathrm{mM}$; Y305F: $K_{i}$ ${ }_{\mathrm{pNPG}}=4.78 \pm 0.44 \mathrm{mM}$ ). It is likely that the GH3 BGLs with either Cyc, Gly, Val, or Ala at position 305 have similar kinetic profiles as the Y305C-substituted BGL1, and supports the hypothesis that transglycosidation is functionally significant in natural cellulase systems [64].

To investigate the structure/function relationship between position 305 residue and the transglycosidation reaction, we mapped its location using the crystal structure of a GH3 BGL from $A$. aculeatus. The AaBGL1 structure shows that three residues form the GH3 BGL +1 subsite and includes the position 305 residue. Since transglycosidation reactions are based on the affinity for acceptor in the +1 subsite, our data showing the control of hydrolytic versus transglycosidase activity by the position 305 residue is consistent with the AaBGL1 crystal structure. The substrate-binding pocket of GH3 BGLs is formed by highly conserved residues in the -1 and +1 subsites, though the distal subsites are less well conserved. Substituting $\operatorname{Trp}^{68}$ in BGL1 has also demonstrated the potential to reduce transglycosidase activity [36]. Unlike substitutions at position 305, those at position 68 cause a decrease in reaction rates for the hydrolysis reaction at substrate concentrations close to $2 \times K_{m}$. Hydrolysis rates for mutants with substitutions at $\operatorname{Trp}^{68}$ are attenuated and reach saturation below the inhibited rates of the wild-type enzyme, and $k_{c a t}$ values are approximately fourfold lower than the wild-type enzyme [36]. In contrast, the position 305 substituted variants reached saturation above the wild-type ${ }_{a p p} V_{\text {max }}$. Alignments show that the position 305 is the least well conserved residue in the active site. The position 305 residue might therefore acts as a "molecular tuning dial" between the hydrolysis and transglycosidase activities. A comparative study of six BGLS with either Phe (five homologs) or Tyr (one homolog) at position 305 showed that hydrolytic/transglycosidase activities can vary significantly between BGLs with very similar active sites [7]. While only small differences in $K_{m}$ hydrolysis values were observed (1.1-2.95 $\mathrm{mM}$ cellobiose), the range of $K_{m \text { transglycosida- }}$ tion values was much greater (1.3-35 $\mathrm{mM}$ cellobiose). A relationship between $K_{m}$ hydrolysis and $K_{m}$ transglycosidation was established in kinetic profiles, whereby homologs with $K_{m \text { transglycosidation }}$ approaching $K_{m \text { hydrolysis }}$ were more inhibited in the production of glucose than those with $K_{m \text { transglycosidation }}$ well above $K_{m \text { hydrolysis }}$. Closer inspection of the amino acid sequences of these six BGLs and other homologs with either $\mathrm{Phe}^{305}$ or $\mathrm{Tyr}^{305}$ shows that a variable sequence forms part of the loop that coordinates this residue (Fig. 3c). It is possible that this variable sequence creates subtle changes in the orientation of the position 
305 residue and could provide the basis for finer tuning between hydrolytic and transglycosidation reactions.

A second beneficial substitution, Q140L, increased hydrolytic activity by $156 \%$ compared to BGL1 at $2 \mathrm{mM}$ pNPG. The double-substituted Q140L/Y305C variant had slightly higher $K_{m}$ and $K_{i \text { glucose }}$ values compared to the Y305C background, suggesting decreased affinity for substrate and product in the active site. Since $K_{i \text { glu- }}$ cose values could not be calculated for either wild-type or the Q140L BGL1 variant using a substrate inhibition model, we also fit the reaction rates for a substrate range of 0.1-1 mM pNPG to the Micheals-Menten equation under the competitive inhibition model allowing the $K_{i}$ glucose for both enzymes to be approximated. This analysis showed an increase in $K_{m}$ (BGL1 $0.51 \pm 0.04 \mathrm{mM}$ pNPG; Q140L $0.74 \pm 0.03 \mathrm{mM}$ pNPG) that was consistent with the increase in $K_{m}$ observed using data fit to the substrate inhibition model (BGL1 $0.82 \pm 0.12 \mathrm{mM}$ pNPG; Q140L $1.09 \pm 0.06 \mathrm{mM} \mathrm{pNPG})$ and an increased $K_{i \text { glucose }}$ value (BGL1 $1.72 \pm 0.09 \mathrm{mM}$; Q140L $2.73 \pm 0.07 \mathrm{mM}$ ) for the Q140L variant compared to wild type. It is therefore possible that the $K_{m}$ transglycosidation for the Q140L would be slightly higher than wild type, as we observed an increase in $K_{i \text { pNPG }}$ (BGL1 $2.98 \pm 0.46 \mathrm{mM}$; Q140L $3.41 \pm 0.21 \mathrm{mM}$ ). Even though $\mathrm{Gln}^{140}$ is not directly involved in forming the substrate-binding pocket, the proximity of the active site to the position 140 residue could explain the change in $\mathrm{K}_{m}, K_{i}$ glucose and $K_{i \mathrm{pNPG}}$ values. In the AaBGL1 crystal structure and a Phyre ${ }^{2}$ homology model of BGL1 (data not shown), the sidechain nitrogen of $\mathrm{Gln}^{140}$ forms a hydrogen bond with backbone amide oxygen of $\mathrm{Ser}^{93}$. Since Asp ${ }^{92}$ forms part of the -1 subsite, it is possible that the loss of a hydrogen bond between $\mathrm{Ser}^{93}$ and $\mathrm{Gln}^{140}$ of Q140L would cause a subtle change in the affinity for cellobiose and glucose in the substrate-binding pocket, as well as a slight reduction in affinity for acceptor in the +1 subsite.

Three beneficial substitutions (A480V, K494Q, and N557D) were located in the $\beta / \alpha$ domain that mediates a protein-protein interaction between subunits of the AaBGL1 functional dimer. When tested alone or in combination with $\mathrm{Y} 305 \mathrm{C}$, no significant changes were observed in the kinetic constants for these mutants. Interestingly, the GH3 BGL from A. fumigatus has two of the three $\beta / \alpha$ domain substitutions naturally (Val ${ }^{480}$ and $\mathrm{Asp}^{557}$ ), and the GH3 BGL from N. crassa has one of the substitutions naturally $\left(\mathrm{Val}^{480}\right)$. Because we did not determine $k_{\text {cat }}$ values, the functional relationship between these substitutions and the observed increases in apparent $V_{\max }$ remains unclear. However, we suspect that the interaction between subunits could modulate activity though changes in the catalytic turnover number if the quaternary structure is conserved in GH3 BGLs.
Alternatively, the $\beta / \alpha$ domain could be involved in subtle intramolecular domain interactions that lead to the increased apparent $V_{\max }$ caused by the A480V, K494Q, and N557 substitutions.

We also found that the signal peptide was altered in several evolved proteins, providing evidence that the $M F \alpha$ pre-sequence is not optimal for the heterologous expression and secretion of BGL1 in S. cerevisiae. Secretion of heterologously expressed proteins in yeast is often engineered using a signal peptide from the host organism [65-70]. In a previous study by our group, the expression of several fungal BGLs was tested in S. cerevisiae using the MF $\alpha$ signal peptide to mediate protein secretion [25]. While the BGLs had very similar amino acid sequences (>80\% identity) and multiple sequence alignments predict nearly identical substrate-binding pockets, activity varied significantly between enzymes. In the present study, we used a similar system such that the experimental wild-type protein was a fusion construct replacing the native BGL1 signal peptide with the MF $\alpha$ pre-sequence. Since the entire open reading frame was subjected to mutagenesis, we hypothesized that mutations in the MF $\alpha$ pre-sequence could increase expression or secretion. Six of the evolved BGLs were found to have mutations encoding modified signal sequences. We found that the residues at positions 21 or 22 of the MF $\alpha$ peptide were substituted in all of the evolved proteins with mutated signal sequences, where $\mathrm{Val}^{22}$ was replaced with either Ala or Asp in four of the twelve evolved proteins. In a directed evolution study using the MFo prepro-peptide to mediate $\mathrm{ssFc}$ secretion from $S$. cerevisiae, Rakestraw et al. [71] found a V22A substitution in all of the evolved proteins. Surprisingly, the V22A substitution had no effect when tested alone, and only produced an increase in secretion when combined with secondary mutations in the region encoding the MF $\alpha$ pro-sequence. In our study, we chose not to use the MF $\alpha$ pro-sequence since it has been shown to have negative effects on heterologous expression and secretion in a foreign host. [69] We identified two beneficial substitutions at position 22 of the MF $\alpha$ pre-sequence including the previously reported V22A substitution. These results show that a portion of the BGL1 polypeptide may function as a secretory prosequence and requires an optimized MF $\alpha$ pre-sequence for efficient secretion.

\section{Conclusions}

In this study we applied directed evolution to A. niger BGL1 by expressing a library mutant BGLs in S. cerevisiae and used a two-step functional screen to identify improved enzymes. We found a key substitution at $\mathrm{Tyr}^{305}$ that dramatically reduced the inhibitory effect towards the hydrolytic activity of BGL1 that is caused 
by transglycosidation reactions at high substrate concentrations. Using the Y305C variant as a background allowed kinetic data to be fit to the Michaelis-Menten equation. This improved the characterization of Q140L, A480V, K494Q, and N557D variants and allowed kinetic constants to be determined in the absence of substrate inhibition. Experiments using the quadruple-substituted BGL1 variant, DLCV, also showed that the Y305C substituted enzyme can be used in combination with several beneficial substitutions, demonstrating a cumulative effect towards increased activity. This work provides a tool to better understand functional mechanisms that differentiate GH3 BGLs and shows that cellulases can be optimized for high substrate loadings, where the position 305 residue will likely be a critical component of BGL1 derivatives engineered for industrial applications.

\section{Methods}

\section{Molecular biology}

Experiments in yeast were performed using $S$. cer-

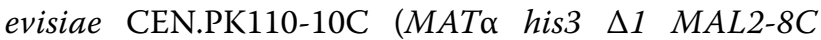
$S U C 2)$. Yeast cultures were grown at $30{ }^{\circ} \mathrm{C}$ in YPD or yeast nitrogen base (YNB) supplemented as required to maintain the auxotrophic selection marker. Plasmids were constructed by in vivo homologous DNA recombination using a pGREG503 derivative with a unique KpnI site and the HIS3 auxotrophic marker [72]. The plasmids were assembled into $S$. cerevisiae by co-transforming linearized plasmid and DNA fragments using the lithium acetate/carrier DNA method. DNA parts were designed with at least $50 \mathrm{bp}$ regions of homology to mediate recombination. Transformants were cultured on solid media for selection (YNB $+2 \%$ glucose containing $1.5 \%$ agar and supplemented with synthetic dropout media without histidine). After transformation, assembled plasmids were extracted from $S$. cerevisiae and propagated in E. coli for sequencing. Verified constructs were transformed back into $S$. cerevisiae for subsequent experiments. DNA fragments used in assembling plasmids were amplified by PCR using Phusion High-Fidelity DNA polymerase (Thermo Scientific) and primers listed in Additional file 1: Table S1. For site-directed mutagenesis, full-length genes were constructed by PCR overlap extension using DNA parts amplified with primers containing the desired nucleotide substitutions. The DNA parts used for in vivo recombination were purified by gel extraction with the GeneJET Gel Extraction Kit (Thermo Scientific). Plasmids were purified from E. coli and $S$. cerevisiae using the GeneJET plasmid miniprep kit (Thermo Scientific). Yeast cells were treated with lytic enzyme (MP Biomedicals) for $1 \mathrm{~h}$ prior to the lysis step for plasmid extractions.

\section{Expression of a secreted BGL in S. cerevisiae}

Three plasmids were constructed to express bgll and assemble mutagenized gene libraries in $S$. cerevisiae (Fig. 1a). The assembly plasmid, pKL022, was constructed by co-transforming AscI/KpnI-linearized pGREG503, the $S c P_{\mathrm{TDH} 3}$ promoter, and the $S c T_{\mathrm{CYC} 1}$ terminator into S. cerevisiae. The promoter and terminator were amplified by PCR using pGREG503-based constructs as templates such that the $5^{\prime}$ end of the $S c P_{\mathrm{TDH} 3}$ promoter and the $3^{\prime}$ end of the $S c T_{\mathrm{CYC} 1}$ terminator had at least a $50 \mathrm{bp}$ of homology with the linearized plasmid. The region between the $S c P_{\mathrm{TDH} 3}$ promoter and the $S c T_{\mathrm{CYC} 1}$ terminator was designed with an 86 nucleotide sequence that included a XhoI restriction site, linker, $\mathrm{His}_{6}$ tag, and a stop codon. A second plasmid, pKL024, was constructed similarly using the XhoI-linearized pKL022 and a 500-bp synthetic DNA fragment (Integrated DNA Technologies) designed to insert nucleotides encoding the MF $\alpha$ pre-sequence in pKL022. The BGL1 expression plasmid, pKL029, was constructed by co-transforming S. cerevisiae with XhoI-linearized pKL024 and the PCR-amplified bgl1 gene [25]. Secretion was engineered to be under control of the $S$. cerevisiae MF $\alpha$ pre-peptide by replacing the first 21 codons from the wild-type gene with the first 24 codons from the $M F \alpha$ gene to construct $M F \alpha-b g l 1$ fusion gene (experimental wild type). The primers used to amplify bgll were designed to replace the native signal sequence with the MFo sequence at the $5^{\prime}$ end of the gene, and the linker region of the pKL022 and pKL024 plasmids at the $3^{\prime}$ end (Fig. 1a). PCR amplification of the bgll gene from pKL029 with the primer pair KL50 and KL51 produced a DNA fragment that would recombine with XhoI-linearized pKL022 when co-transformed in S. cerevisiae, and would express a functionally secreted BGL.

\section{Error-prone PCR of $b g / 1$}

Error-prone PCR was used to generate sequence diversity of the bgll gene. The region between the start codon and the linker region of pKL029 was mutagenized by PCR using Taq polymerase under high $\mathrm{MgCl}_{2}$ conditions $(5 \mathrm{mM})$, with an unbalanced dNTP mixture $(0.2 \mathrm{mM}$ dATP, $0.2 \mathrm{mM}$ dGTP, $1 \mathrm{mM}$ dTTP, and $1 \mathrm{mM} \mathrm{dCTP)}$ and in the presence of $\mathrm{MnCl}_{2}(0.15 \mathrm{mM})$ using the KL50/ KL51 primer pair. To generate a library of bgl1 mutants, the PCR product from several reactions was pooled, mixed with XhoI-linearized pKL022 and transformed into $S$. cerevisiae by electroporation. Electrocompetent S. cerevisiae cells were prepared from $250 \mathrm{ml}$ of a YPD culture (O.D. $\left.{ }_{600}=1.6\right)$ in $50 \mathrm{ml}$ of a $1 \mathrm{M}$ sorbitol solution containing $0.1 \mathrm{M} \mathrm{LiAc}$ and $10 \mathrm{mM}$ DTT incubated for $1 \mathrm{~h}$ at room temperature with gentle mixing. After the 
LiAc/DTT treatment, cells were washed twice in $50 \mathrm{ml}$ of $1 \mathrm{M}$ sorbitol and suspended to a final volume of $5 \mathrm{ml}$ in ice-cold $1 \mathrm{M}$ sorbitol. Aliquots $(0.2 \mathrm{ml})$ of the electrocompetent cell suspension were removed, mixed with $1.5 \mu \mathrm{g}$ of PCR product, $1.5 \mu \mathrm{g}$ of Xhol-linearized pKL022, and electroporated $(2.5 \mathrm{kV}, 25 \mu \mathrm{F})$ using an ice-chilled cuvette. Cells from ten transformations were pooled, and a small quantity of the mixture was removed to determine the transformation efficiency. The remainder of the mixture was transferred to $100 \mathrm{ml}$ of selective media and grown for 2 days at $30^{\circ} \mathrm{C}$ with shaking. The transformation pool was then harvested by centrifugation, suspended in $10 \mathrm{~mL}$ of YNB containing $20 \%$ glycerol and stored at $-80^{\circ} \mathrm{C}$ in $0.5 \mathrm{~mL}$ aliquots.

\section{Selection of improved BGLs}

Improved BGLs were identified using a growth selection with cellobiose as the sole carbon source followed by an endpoint activity assay using $p$-nitrophenyl- $\beta$-Dglucopyranoside (pNPG) as a substrate. For growth selection, an overnight culture was used to inoculate $50 \mathrm{ml}$ of fresh media containing glucose at an O.D. ${ }_{600}=0.05$ and after $6 \mathrm{~h}$ cells were spread on solid YNB $+1 \%$ cellobiose. The cell density for growth on solid media containing cellobiose was optimized to approximately 13 cells/ $\mathrm{cm}^{2}$. Cells were also grown on solid YNB $+2 \%$ glucose for comparison. After 3-4 days of growth, the largest colonies were picked and used to inoculate $200 \mu \mathrm{l}$ of $\mathrm{YNB}+2 \%$ glucose in 96 -well plates to supply enzymes for the endpoint activity assay. Four wells from each 96-well plate were inoculated with cells containing pKL029 to express BGL1 as a control. The 96-well plates were sealed in plastic bags and incubated at $30{ }^{\circ} \mathrm{C}$ without shaking for two days. Twenty $\mu \mathrm{l}$ of the culture was transferred to $180 \mu \mathrm{l}$ of fresh media and grown for an additional 2 days at $30{ }^{\circ} \mathrm{C}$ without shaking. The O.D. ${ }_{600}$ was measured for each culture and $50 \mu \mathrm{l}$ of supernatant was transferred to $150 \mu \mathrm{l}$ of a $66.6 \mathrm{mM}$ citrate buffer, $\mathrm{pH}$ 5.0, containing $2.66 \mathrm{mM}$ pNPG in 96-well plates. Reactions were incubated at room temperature for $30 \mathrm{~min}$ and quenched with $20 \mu \mathrm{l}$ of $1 \mathrm{M} \mathrm{NaOH}$. The amount of $p$-nitrophenol ( $\mathrm{pNP}$ ) released was determined by measuring the absorbance at $405 \mathrm{~nm}$ using the extinction coefficient $18 \mathrm{mM}^{-1} \mathrm{~cm}^{-1}$ and normalized to cell density. Strains with BGL activities greater than WT $+2 \mathrm{SD}$ were streaked on solid YNB $+2 \%$ glucose media, and three colonies were re-tested using the same endpoint assay. Strains producing BGLs that exceeded a WT + 2SD threshold of activity were chosen for further analysis.

\section{BGL activity assays}

The activities of BGL variants were compared to the experimental wild type using a time course assay measuring the release of pNP from pNPG. For protein production, fresh YNB $+2 \%$ glucose media supplemented with synthetic dropout media lacking histidine was inoculated with $0.5 \mathrm{ml}$ of overnight culture and grown at $30{ }^{\circ} \mathrm{C}$ for $48 \mathrm{~h}$. Cells were removed by centrifugation and the supernatants were filtered using a $0.2 \mu \mathrm{M}$ nylon membrane. Reactions were performed at $30{ }^{\circ} \mathrm{C}$ in $2 \mathrm{ml}$ microcentrifuge tubes by adding $200 \mu \mathrm{l}$ of $16 \mathrm{mM}$ pNPG to a mixture of $1 \mathrm{ml}$ of $80 \mathrm{mM}$ citrate buffer, $\mathrm{pH}$ 5.0, and $400 \mu \mathrm{l}$ of culture supernatant. Two hundred $\mu \mathrm{l}$ samples were removed from the reactions at time intervals over a ten-minute period (five data points) and transferred to $20 \mu \mathrm{l}$ of $1 \mathrm{M} \mathrm{NaOH}$. The amount of pNP released was measured at $405 \mathrm{~nm}$ and activities were calculated using the linear portion of the curve containing at least three time points. Reactions were performed in biological triplicate using cultures inoculated from individual colonies. Assay components were pre-incubated at $30{ }^{\circ} \mathrm{C}$ for $60 \mathrm{~min}$ prior to adding substrate.

\section{Enzyme kinetics}

Kinetic experiments using pNPG as the substrate were performed in 96-well plates at $30^{\circ} \mathrm{C}$. Reactions were initiated by adding $50 \mu \mathrm{l}$ of culture supernatant or $50 \mu \mathrm{l}$ of a $0.01 \mu \mathrm{g} / \mu \mathrm{l}$ concentrated protein preparation to $150 \mu \mathrm{l}$ of a $66 \mathrm{mM}$ citrate buffer solution (pH 5.0) containing pNPG in a range from $0.1-10 \mathrm{mM}$ (final concentration). Glucose was tested in a range from $0-100 \mathrm{mM}$ (final concentration) at each PNPG concentration. Reactions were stopped 5 min after adding enzyme by transferring $100 \mu \mathrm{l}$ of the assay mixture to $10 \mu \mathrm{l}$ of $1 \mathrm{M} \mathrm{NaOH}$ in 96-well plates.

Assays using cellobiose as the substrate were performed in 96 -well plates at $30^{\circ} \mathrm{C}$ with a final reaction volume of $200 \mu \mathrm{l}$ in $5 \mathrm{mM}$ citrate buffer, pH 5.0. Cellobiose was tested at a range from $2-75 \mathrm{mM}$ (final concentration). BGL1 was also tested at a 0.5 and $1 \mathrm{mM}$ cellobiose (final concentration). Reactions were started by adding $50 \mu \mathrm{l}$ of culture supernatant to $150 \mu \mathrm{l}$ of the citrate/cellobiose solution and stopped after 5 min by transferring $100 \mu \mathrm{l}$ of the mixture to $400 \mu \mathrm{l}$ of glucose assay solution (62.5 mM Tris-HCL, pH 8.3, $1.25 \mathrm{mM}$ ATP, $1.875 \mathrm{mM}$ $\mathrm{NAD}, 12.5 \mathrm{mM} \mathrm{MgCl}, 12.5 \mathrm{U} / \mathrm{ml}$ hexokinase (Sigma), and $12.5 \mathrm{U} / \mathrm{ml}$ glucose-6-phosphate dehydrogenase (Sigma)) and incubated for $30 \mathrm{~min}$ at room temperature. The amount of glucose released was determined by measuring the amount of NADH produced at $340 \mathrm{~nm}$, using the extinction coefficient $6220 \mathrm{M}^{-1} \mathrm{~cm}^{-1}$.

For experiments using concentrated protein preparations, $100 \mathrm{ml}$ of culture supernatant was filtered using a $10 \mathrm{kDa}$ cutoff membrane (VivaSpin) to a final volume of $1 \mathrm{ml}$. The retentate was diluted to $15 \mathrm{ml}$ using $5 \mathrm{mM}$ citrate buffer, $\mathrm{pH}$ 5.0, and buffer exchange process was 
repeated twice before reducing the sample volume to 500-800 $\mu \mathrm{l}$. Protein concentrations were determined using a Coomassie Protein Assay Kit (Thermo Scientific) with BSA as a standard. Concentrate samples were analyzed by SDS-PAGE with and without PNGase F (New England BioLabs) treatment (data not shown). Kinetic parameters for steady-state reactions were determined using GraphPad Prism enzyme kinetics module.

\section{Analysis of reaction products}

Reactions using $40 \mathrm{mM}$ pNPG and $50 \mathrm{mM}$ cellobiose as substrate were performed using the same conditions as for enzyme kinetics. Ten $\mu$ l samples were removed from $200 \mu$ reactions at time intervals and stopped using $1 \mu \mathrm{l}$ of $1 \mathrm{M} \mathrm{NaOH}$. One $\mu \mathrm{l}$ aliquots from each time interval were applied to a silica TLC plates (Whatman), eluted with a $n$-butanol, ethyl acetate, 2-propanol, acetic acid, and water (1:3:2:1:1) and developed as previously described [63].

\section{Additional file}

Additional file 1. Table S1. Primers used in this study.

\section{Abbreviations}

BGL: $\beta$-glucosidase; CBP: consolidated bioprocessing; CBH: cellobiohydrolase; EGL: endoglucanase; GH3: glycosyl hydrolase family 3; MFa: Saccharomyces cerevisiae mating pheromone a factor; PCR: polyclonal chain reaction; PNPG: p-nitrophenyl- $\beta$-D-glucopyranoside; pNP: $p$-nitrophenol; TLC: thin-layer chromatography.

\section{Authors' contributions}

$\mathrm{KL}$ designed and conducted most of the experiments, analyzed the results, and wrote the paper. MM performed targeted mutagenesis and performed preliminary analysis of mutant BGLS. VJJM designed experiments, analyzed results, and wrote the paper with $\mathrm{KL}$. All authors read and approved the final manuscript.

\section{Acknowledgements}

The NSERC Bioconversion Network (NETGP350246-07), BioFuelNet, and a Canada Research Chair to VJJM, supported this research.

\section{Competing interests}

The authors declare that they have no competing interests.

Received: 14 October 2015 Accepted: 22 February 2016

Published online: 03 March 2016

\section{References}

1. Ragauskas AJ, Williams CK, Davison BH, Britovsek G, Cairney J, Eckert CA, Frederick WJ, Hallett JP, Leak DJ, Liotta CL, Mielenz JR, Murphy R, Templer $\mathrm{R}$, Tschaplinski T. The path forward for biofuels and biomaterials. Science. 2006;311:484-9.

2. Doran-Peterson J, Jangid A, Brandon SK, DeCrescenzo-Henriksen E, Dien $B$, Ingram LO. Simultaneous saccharification and fermentation and partial saccharification and co-fermentation of lignocellulosic biomass for ethanol production. Methods Mol Biol. 2009;581:263-80.
3. Lynd LR, van Zyl WH, McBride JE, Laser M. Consolidated bioprocessing of cellulosic biomass: an update. Curr Opin Biotechnol. 2005;16:577-83.

4. Lynd LR, Weimer PJ, van ZyI WH, Pretorius IS. Microbial cellulose utilization: fundamentals and biotechnology. Microbiol Mol Biol Rev. 2002;66:506-77.

5. Bhat MK, Bhat S. Cellulose degrading enzymes and their potential industrial applications. Biotechnol Adv. 1997;15:583-620.

6. Shewale JG. Beta-glucosidase: its role in cellulase synthesis and hydrolysis of cellulose. Int J Biochem. 1982;14:435-43.

7. Bohlin C, Praestgaard E, Baumann MJ, Borch K, Praestgaard J, Monrad RN, Westh P. A comparative study of hydrolysis and transglycosylation activities of fungal $\beta$-glucosidases. Appl Microbiol Biotechnol. 2012;97:159-69.

8. Kawai R, Igarashi K, Kitaoka M, Ishii T, Samejima M. Kinetics of substrate transglycosylation by glycoside hydrolase family 3 glucan (1->3)-betaglucosidase from the white-rot fungus Phanerochaete chrysosporium. Carbohydr Res. 2004;339:2851-7

9. Christakopoulos P, Goodenough PW, Kekos D, Macris BJ, Claeyssens M, Bhat MK. Purification and characterisation of an extracellular betaglucosidase with transglycosylation and exo-glucosidase activities from Fusarium oxysporum. Eur J Biochem. 1994;224:379-85.

10. Xiao Z, Zhang X, Gregg DJ, Saddler JN. Effects of sugar inhibition on cellulases and beta-glucosidase during enzymatic hydrolysis of softwood substrates. Appl Biochem Biotechnol. 2004;113-116:1115-26.

11. Chauve M, Mathis H, Huc D, Casanave D, Monot F, Ferreira NL, Lopes Ferreira N. Comparative kinetic analysis of two fungal beta-glucosidases. Biotechnol Biofuels. 2010;3:3.

12. Bohlin C, Olsen SN, Morant MD, Patkar S, Borch K, Westh P. A comparative study of activity and apparent inhibition of fungal $\beta$-glucosidases. Biotechnol Bioeng. 2010;107:943-52.

13. Rajasree KP, Mathew GM, Pandey A, Sukumaran RK. Highly glucose tolerant $\beta$-glucosidase from Aspergillus unguis: NII 08123 for enhanced hydrolysis of biomass. J Ind Microbiol Biotechnol. 2013;40:967-75.

14. Riou C, Salmon JM, Vallier MJ, Günata Z, Barre P. Purification, characterization, and substrate specificity of a novel highly glucose-tolerant beta-glucosidase from Aspergillus oryzae. Appl Environ Microbiol. 1998;64:3607-14.

15. Günata Z, Vallier M. Production of a highly glucose-tolerant extracellular $\beta$-glucosidase by three Aspergillus strains. Biotechnol Lett. 1999;21:219-223.

16. Saha BC, Bothast RJ. Production, purification, and characterization of a highly glucose-tolerant novel beta-glucosidase from Candida peltata. Appl Environ Microbiol. 1996;62:3165-70.

17. Singhania RR, Patel AK, Sukumaran RK, Larroche C, Pandey A. Role and significance of beta-glucosidases in the hydrolysis of cellulose for bioethanol production. Bioresour Technol. 2013;127:500-7.

18. Fujita Y, Takahashi S, Ueda M, Tanaka A, Okada H, Morikawa Y, Kawaguchi T, Arai M, Fukuda H, Kondo A. Direct and efficient production of ethanol from cellulosic material with a yeast strain displaying cellulolytic enzymes. Appl Environ Microbiol. 2002;68:5136-41.

19. Kotaka A, Bando H, Kaya M, Kato-Murai M, Kuroda K, Sahara H, Hata Y, Kondo A, Ueda M. Direct ethanol production from barley beta-glucan by sake yeast displaying Aspergillus oryzae beta-glucosidase and endoglucanase. J Biosci Bioeng. 2008;105:622-7.

20. Jeon E, Hyeon JE, Eun LS, Park BS, Kim SW, Lee J, Han SO. Cellulosic alcoholic fermentation using recombinant Saccharomyces cerevisiae engineered for the production of Clostridium cellulovorans endoglucanase and Saccharomycopsis fibuligera beta-glucosidase. FEMS Microbiol Lett. 2009;301:130-6.

21. Wen F, Sun J, Zhao H. Yeast surface display of trifunctional minicellulosomes for simultaneous saccharification and fermentation of cellulose to ethanol. Appl Environ Microbiol. 2010;76:1251-60.

22. Machida M, Ohtsuki I, Fukui S, Yamashita I. Nucleotide sequences of Saccharomycopsis fibuligera genes for extracellular beta-glucosidases as expressed in Saccharomyces cerevisiae. Appl Environ Microbiol. 1988;54:3147-55.

23. Wood BE, Ingram LO. Ethanol production from cellobiose, amorphous cellulose, and crystalline cellulose by recombinant Klebsiella oxytoca containing chromosomally integrated Zymomonas mobilis genes for ethanol production and plasmids expressing thermostable cellulase genes from Clostridium thermocellum. Appl Environ Microbiol. 1992;58:2103-10. 
24. Saitoh S, Tanaka T, Kondo A. Co-fermentation of cellulose/xylan using engineered industrial yeast strain OC-2 displaying both $\beta$-glucosidase and $\beta$-xylosidase. Appl Microbiol Biotechnol. 2011;91:1553-9.

25. Wilde C, Gold ND, Bawa N, Tambor JHM, Mougharbel L, Storms R, Martin $\mathrm{VJJJ}$. Expression of a library of fungal $\beta$-glucosidases in Saccharomyces cerevisiae for the development of a biomass fermenting strain. Appl Microbiol Biotechnol. 2012:95:647-59.

26. McBride JE, Zietsman JJ, Van Zyl WH, Lynd LR. Utilization of cellobiose by recombinant $\beta$-glucosidase-expressing strains of Saccharomyces cerevisiae: characterization and evaluation of the sufficiency of expression. Enzyme Microb Technol. 2005;37:93-101.

27. Guo ZP, Zhang L, Ding ZY, Gu ZH, Shi GY. Development of an industrial ethanol-producing yeast strain for efficient utilization of cellobiose. Enzyme Microb Technol. 2011;49:105-12.

28. Tsai SL, Oh J, Singh S, Chen R, Chen W. Functional assembly of minicellulosomes on the Saccharomyces cerevisiae cell surface for cellulose hydrolysis and ethanol production. Appl Environ Microbiol. 2009;75:6087-93.

29. Yanase S, Yamada R, Kaneko S, Noda H, Hasunuma T, Tanaka T, Ogino C, Fukuda $\mathrm{H}$, Kondo A. Ethanol production from cellulosic materials using cellulase-expressing yeast. Biotechnol J. 2010;5:449-55.

30. Jeon E, Hyeon JE, Suh DJ, Suh YW, Kim SW, Song KH, Han SO. Production of cellulosic ethanol in Saccharomyces cerevisiae heterologous expressing Clostridium thermocellum endoglucanase and Saccharomycopsis fibuligera beta-glucosidase genes. Mol Cells. 2009;28:369-73.

31. Ma L, Zhang J, Zou G, Wang C, Zhou Z. Improvement of cellulase activity in Trichoderma reesei by heterologous expression of a betaglucosidase gene from Penicillium decumbens. Enzyme Microb Technol. 2011;49:366-71.

32. Dashtban M, Qin W. Overexpression of an exotic thermotolerant $\beta$-glucosidase in Trichoderma reesei and its significant increase in cellulolytic activity and saccharification of barley straw. Microb Cell Fact. 2012;11:63.

33. Park EH, Shin YM, Lim YY, Kwon TH, Kim DH, Yang MS. Expression of glucose oxidase by using recombinant yeast. J Biotechnol. 2000;81:35-44.

34. Himmel ME, Adney WS, Fox JW, Mitchell DJ, Baker JO. Isolation and characterization of two forms of $\beta$-d-glucosidase from Aspergillus niger. Appl Biochem Biotechnol. 1993;39-40:213-25.

35. Araujo EF, Barros EG, Caldas RA, Silva DO. Beta-glucosidase activity of a thermophilic cellulolytic fungus. Humicola sp. Biotechnol Lett. 1983;5:781-4

36. Seidle HF, Allison SJ, George E, Huber RE. Trp-49 of the family 3 beta-glucosidase from Aspergillus niger is important for its transglucosidic activity: creation of novel beta-glucosidases with low transglucosidic efficiencies. Arch Biochem Biophys. 2006:455:110-8.

37. Van Rooyen R, Hahn-Hägerdal B, La Grange DC, van Zyl WH. Construction of cellobiose-growing and fermenting Saccharomyces cerevisiae strains. J Biotechnol. 2005;120:284-95.

38. Gundllapalli SB, Pretorius IS, Cordero Otero RR. Effect of the cellulosebinding domain on the catalytic activity of a beta-glucosidase from Saccharomycopsis fibuligera. J Ind Microbiol Biotechnol. 2007;34:413-21.

39. Kotaka A, Sahara H, Kuroda K, Kondo A, Ueda M, Hata Y. Enhancement of beta-glucosidase activity on the cell-surface of sake yeast by disruption of SED1. J Biosci Bioeng. 2010;109:442-6.

40. Inokuma K, Hasunuma T, Kondo A. Efficient yeast cell-surface display of exo- and endo-cellulase using the SED1 anchoring region and its original promoter. Biotechnol Biofuels. 2014;7:8.

41. Suzuki K, Sumitani J, Nam Y, Nishimaki T, Tani S, Wakagi T, Kawaguchi T, Fushinobu S. Crystal structures of glycoside hydrolase family 3 $\beta$-glucosidase 1 from Aspergillus aculeatus. Biochem J. 2013;452:211-21.

42. Pozzo T, Pasten JL, Karlsson EN, Logan DT. Structural and functional analyses of beta-glucosidase 3B from Thermotoga neapolitana: a thermostable three-domain representative of glycoside hydrolase 3. J Mol Biol. 2010;397:724-39.

43. Jeng WY, Wang NC, Lin MH, Lin CT, Liaw YC, Chang WJ, Liu Cl, Liang PH, Wang AHJ. Structural and functional analysis of three $\beta$-glucosidases from bacterium Clostridium cellulovorans, fungus Trichoderma reesei and termite Neotermes koshunensis. J Struct Biol. 2011;173:46-56.

44. Sørensen A, Lübeck M, Lübeck PS, Ahring BK. Fungal Beta-glucosidases: a bottleneck in industrial use of lignocellulosic materials. Biomolecules. 2013;3:612-31.
45. Johannes TW, Zhao H. Directed evolution of enzymes and biosynthetic pathways. Curr Opin Microbiol. 2006;9:261-7.

46. Farinas ET, Bulter T, Arnold FH. Directed enzyme evolution. Curr Opin Biotechnol. 2001;12:545-51.

47. Murashima K, Kosugi A, Doi RH. Thermostabilization of cellulosomal endoglucanase EngB from Clostridium cellulovorans by in vitro DNA recombination with non-cellulosomal endoglucanase EngD. Mol Microbiol. 2002;45:617-26.

48. Kim YS, Jung HC, Pan JG. Bacterial cell surface display of an enzyme library for selective screening of improved cellulase variants. Appl Environ Microbiol. 2000;66:788-93.

49. Wang T, Liu X, Yu Q, Zhang X, Qu Y, Gao P, Wang T. Directed evolution for engineering $\mathrm{pH}$ profile of endoglucanase III from Trichoderma reesei. Biomol Eng. 2005;22:89-94.

50. Arrizubieta MJ, Polaina J. Increased thermal resistance and modification of the catalytic properties of a beta-glucosidase by random mutagenesis and in vitro recombination. J Biol Chem. 2000;275:28843-8.

51. Lebbink JH, Kaper T, Bron P, van der Oost J, de Vos WM. Improving lowtemperature catalysis in the hyperthermostable Pyrococcus furiosus betaglucosidase CelB by directed evolution. Biochemistry. 2000;39:3656-65.

52. Gonzalez-Blasco G, Sanz-Aparicio J, Gonzalez B, Hermoso JA, Polaina J. Directed evolution of beta-glucosidase A from Paenibacillus polymyxa to thermal resistance. J Biol Chem. 2000;275:13708-12.

53. Hardiman E, Gibbs M, Reeves R, Bergquist P. Directed evolution of a thermophilic beta-glucosidase for cellulosic bioethanol production. Appl Biochem Biotechnol. 2010;161:301-12.

54. McCarthy JK, Uzelac A, Davis DF, Eveleigh DE. Improved catalytic efficiency and active site modification of 1,4-beta-D-glucan glucohydrolase A from Thermotoga neapolitana by directed evolution. J Biol Chem. 2004;279:11495-502.

55. Pei XQ, Yi ZL, Tang CG, Wu ZL. Three amino acid changes contribute markedly to the thermostability of $\beta$-glucosidase BgIC from Thermobifida fusca. Bioresour Technol. 2011;102:3337-42.

56. Eriksen DT, Hsieh PCH, Lynn P, Zhao H. Directed evolution of a cellobiose utilization pathway in Saccharomyces cerevisiae by simultaneously engineering multiple proteins. Microb Cell Fact. 2013;12:61.

57. Du J, Yuan Y, Si T, Lian J, Zhao H. Customized optimization of metabolic pathways by combinatorial transcriptional engineering. Nucleic Acids Res. 2012;40:e142.

58. Kim B, Du J, Eriksen DT, Zhao H. Combinatorial design of a highly efficient xylose-utilizing pathway in Saccharomyces cerevisiae for the production of cellulosic biofuels. Appl Environ Microbiol. 2013;79:931-41.

59. Romero PA, Arnold FH. Exploring protein fitness landscapes by directed evolution. Nat Rev Mol Cell Biol. 2009;10:866-76.

60. Crombie HJ, Chengappa S, Hellyer A, Reid JSG. A xyloglucan oligosaccharide-active, transglycosylating-D-glucosidase from the cotyledons of nasturtium (Tropaeolum majus L) seedlings - purification, properties and characterization of a cDNA clone. Plant J. 1998;15:27-38.

61. Korotkova OG, Semenova MV, Morozova WV, Zorov IN, Sokolova LM, Bubnova TM, Okunev ON, Sinitsyn AP. Isolation and properties of fungal ß-glucosidases. Biochem. 2009;74:569-77.

62. Langston J, Sheehy N, Xu F. Substrate specificity of Aspergillus oryzae family 3 beta-glucosidase. Biochim Biophys Acta. 2006;1764:972-8.

63. Seidle HF, Marten I, Shoseyov O, Huber RE. Physical and kinetic properties of the family 3 beta-glucosidase from Aspergillus niger which is important for cellulose breakdown. Protein J. 2004;23:11-23.

64. Seidle HF, Huber RE. Transglucosidic reactions of the Aspergillus niger family 3 beta-glucosidase: qualitative and quantitative analyses and evidence that the transglucosidic rate is independent of $\mathrm{pH}$. Arch Biochem Biophys. 2005;436:254-64.

65. Brake AJ, Merryweather JP, Coit DG, Heberlein UA, Masiarz FR, Mullenbach GT, Urdea MS, Valenzuela P, Barr PJ. Alpha-factor-directed synthesis and secretion of mature foreign proteins in Saccharomyces cerevisiae. Proc Natl Acad Sci U S A. 1984;81:4642-6.

66. Kjaerulff S, Jensen MR. Comparison of different signal peptides for secretion of heterologous proteins in fission yeast. Biochem Biophys Res Commun. 2005;336:974-82.

67. Lee MA, Cheong KH, Shields D, Park SD, Hong SH. Intracellular trafficking and metabolic turnover of yeast prepro-alpha-factor-SRIF precursors in GH3 cells. Exp Mol Med. 2002;34:285-93. 
68. Fitzgerald I, Glick BS. Secretion of a foreign protein from budding yeasts is enhanced by cotranslational translocation and by suppression of vacuolar targeting. Microb Cell Fact. 2014;13:125.

69. Lin-Cereghino GP, Stark CM, Kim D, Chang J, Shaheen N, Poerwanto H, Agari K, Moua P, Low LK, Tran N, Huang AD, Nattestad M, Oshiro KT, Chang JW, Chavan A, Tsai JW, Lin-Cereghino J. The effect of a-mating factor secretion signal mutations on recombinant protein expression in Pichia pastoris. Gene. 2013;519:311-7.

70. Ahmad M, Hirz M, Pichler H, Schwab H. Protein expression in Pichia pastoris: recent achievements and perspectives for heterologous protein production. Appl Microbiol Biotechnol. 2014;98:5301-17.

71. Rakestraw JA, Sazinsky SL, Piatesi A, Antipov E, Wittrup KD. Directed evolution of a secretory leader for the improved expression of heterologous proteins and full-length antibodies in Saccharomyces cerevisiae. Biotechnol Bioeng. 2009;103:1192-201.

72. Fossati E, Ekins A, Narcross L, Zhu Y, Falgueyret J-P, Beaudoin GAW, Facchini PJ, Martin VJJ. Reconstitution of a 10-gene pathway for synthesis of the plant alkaloid dihydrosanguinarine in Saccharomyces cerevisiae. Nat Commun. 2014;5:3283.

73. Sievers F, Wilm A, Dineen D, Gibson TJ, Karplus K, Li W, Lopez R, McWilliam $H$, Remmert M, Söding J, Thompson JD, Higgins DG. Fast, scalable generation of high-quality protein multiple sequence alignments using Clustal Omega. Mol Syst Biol. 2011;7:539.

\section{Submit your next manuscript to BioMed Central and we will help you at every step:}

- We accept pre-submission inquiries

- Our selector tool helps you to find the most relevant journal

- We provide round the clock customer support

- Convenient online submission

- Thorough peer review

- Inclusion in PubMed and all major indexing services

- Maximum visibility for your research

Submit your manuscript at www.biomedcentral.com/submit
() Biomed Central 